\title{
Can We Act Ethically? Implications of Determinism, Chaos Theory and Unintended Consequences
}

\author{
John Tsalikis
}

$\mathrm{PhD}$, Professor, Department of Marketing, Florida International University, USA

\begin{abstract}
This paper looks at the question of whether people can act ethically from the perspective of determinism, chaos theory, and unintended consequences. These concepts negate the idea that ethical acts are always followed by ethical results. Sometimes the opposite might happen, an ethical act could be followed by an unethical result. The paper begins by presenting the various definitions of "ethics", including Taylor's definition of ethics as "an inquiry into the nature and grounds of moral judgments, standards, and rules of conduct relating to marketing decisions and marketing situations". Consequently, the predominant philosophical normative ethical theories are divided into three groups: (1) consequential theories - those that deal exclusively with the consequences of an action (egoism, and utilitarianism); (2) single-rule nonconsequential - those that deal with a single rule (golden rule, and Kant's categorical imperative); and (3) multiple-rule nonconsequential - those that deal with multiple rules (Ross's prima facie duties, Rawl's maximin principle of justice, and Garrett's Principle of Proportionality). Finally, Protagoras' conception of ethical relativism is presented. The Greek philosopher Protagoras, seems to have believed two things: first, that moral principles cannot be shown to be valid for everybody; and second, that people ought to follow the conventions of their own group. The above ethical theories are seen through the eyes of Newton's perception of Determinism of the world as a clockwork, where a cause is always followed by a predictable effect. It assumes that causation is absolute and all events are completely determined by previously existing causes. This deterministic point of view is juxtaposed with the concept of unintended consequences and the ideas of chaos theory including Sensitivity to Initial Conditions, Dimensionality, and areas of Determinism being followed by areas of Chaos. The conclusion is that reality is too chaotic and dynamic to predict the causal effects of ethical actions.
\end{abstract}

Keywords: ethics, determinism, chaos theory, unintended consequences.

JEL Classification: B55.

(C) The Author, 2018. This article is published with open access at Sumy State University.

\section{Introduction}

A great deal of research on ethics has proceeded by asking participants to read an ethically sensitive scenario and to give a response on the ethicality of the presented action. There is no question that people perceive some acts as ethical and others less so. Right or wrong, while it varies by culture, the current zeitgeist, and from individual to individual, it is imbedded in the human DNA. It is a common belief in both our religious dogmas and our personal understanding that doing ethical deeds will result in ethical results. This paper will combine the ideas of determinism, chaos theory and unintended consequences to establish the virtual impossibility of the connection of behaving ethically leading to ethical results.

\section{Definition of Ethics}

The following definition of ethics and philosophical Normative Ethical Theories were first presented in the first author's dissertation and later in Tsalikis and Fritzsche (2012). "Unethical" acts were committed throughout history. Christianity has Adam eating the forbidden fruit, Cain murdering his brother. The majority of the ancient Greek philosophers devoted much of their time to developing theories of ethics. The early theories studied ethics from a normative perspective, meaning that they were concerned with "constructing and justifying the moral standards and codes that one ought to follow" (Vitell, 1986). On the other side, a positive perspective of ethics attempts to describe and explain how individuals actually behave in ethical situations. One of the major preoccupations of ethical theorists was to create a definition of ethics. As with the majority of concepts, ethics was defined differently by different theorists. Beauchamp and Bowie (1983: 3) define ethics as the "inquiry into theories of what is good and evil and into what is right and wrong, and thus is inquiry into what we ought and ought not to do". Similarly, Runes (1964: 98-100) states that "ethical behavior refers to "just" or "right" standards of behavior between parties in a situation". On the same line, 
Barry (1979a, b) defines ethics as "the study of what constitutes good and bad human conduct, including related actions and values".

Ethics, according to DeGeorge (1982: 13-15), is the study of morality. DeGeorge argues that: Morality is a term used to cover those practices and activities that are considered importantly right and wrong, the rules which govern those activities, and the values that are imbedded, fostered, or pursued by those activities and practices. The morality of a society is related to its mores or the customs accepted by a society or group as being the right and wrong ways to act, as well as to the laws of a society which add legal prohibitions and sanctions to many activities considered to be immoral. Similarly, Taylor (1975: 1) defines ethics as an "inquiry into the nature and grounds of morality," where morality means "moral judgments, standards, and rules of conduct". Vitell (1986) applied Taylor's definition to define marketing ethics as "an inquiry into the nature and grounds of moral judgments, standards, and rules of conduct relating to marketing decisions and marketing situations". From the above definitions of ethics, we see that the term ethics is used interchangeably with morals. Although this usage is acceptable, it is more accurate to restrict the terms morals and morality to the conduct itself. The terms ethics and ethical refer to the study of moral conduct or to the code one follows.

\section{Philosophical Normative Ethical Theories}

Recognizing that the number of these theories is quite significant, only the ethical theories most commonly referred to in the business literature will be presented. The ethical theories are usually divided into three groups:

(1) consequential theories - those that deal exclusively with the consequences of an action;

(2) single-rule nonconsequential - those that deal with a single rule;

(3) multiple-rule nonconsequential - those that deal with multiple rules.

Some philosophers call the first group teleological, while group two they call deontological. Group three is a hybrid of both teleological and deontological theories. Cavanagh et al. (1981) divided the theories of ethics into three categories:

(1) utilitarian theories - evaluating behavior in terms of their consequences;

(2) theories of rights - emphasizing the entitlements or rights of individuals, including the right to free consent, the right to privacy, the right to freedom of conscience, the right to free speech, and the right to due process; (3) theories of justice - focusing on the distributional effects of actions.

\section{Consequential Theories}

Traditionally, many theorists contend that the moral rightness of an action can be determined by looking at its consequences. If the consequences are good, the act is ethical; if bad, the act is unethical. In other words, an ethical act is one that produces at least as great a ratio of good to evil as any other course. An obvious question arises in regard to the consequences. In deciding what to do should we consider the consequences only to oneself? Or should one consider them with respect to everyone involved? That decision hinges on the two main consequential theories - egoism and utilitarianism.

\section{Egoism}

Egoism contends that an act is ethical when it promotes the individual's best long term interests. If an action produces a greater ratio of good to evil for the individual in the long run than any other alternative, then that action is ethical. A major misconception is that all egoists are exponents of hedonism - the view that only pleasure is good in itself and worth seeking. True, some egoists are hedonistic, as was the ancient Greek philosopher Epicurus. But other egoists identify the good with knowledge, rational self-interest and selfactualization. Among the weaknesses of ethical egoism are: (a) ethical egoism would take no stand against even the most blatant business practices (e.g. discrimination, pollution, unsafe products, etc.), and (b) egoism cannot resolve conflicts of egoistic interests among two individuals.

\section{Utilitarianism}

Utilitarianism asserts that we should always act in ways that produce the greatest ratio of good to evil for everyone. It emphasizes the best interest of everyone involved with the action. As originally formulated by notable reformers Jeremy Bentham and John Stuart Mill, utilitarianism has been associated with reform or social improvement. Utilitarianism argues that if it were possible to accurately calculate pleasure and pain, we would subtract the total unhappiness from the total happiness our action would produce, and choose the action which produces the greatest net happiness. While all utilitarians agree on the principle of greatest net utility, they disagree on how this principle should be applied. Some utilitarians would apply it to the act itself; others, to the rule the act falls under. Thus, we get act utilitarianism and rule utilitarianisms. Act utilitarianism 
maintains that the right act is the one that produces the greatest ratio of good to evil for all concerned. On the other hand, rule utilitarianism asks us to determine the worth of the rule under which an action falls. If keeping the rule produces more total good than breaking it, we should keep it. Act utilitarianism has provided the basis for an ethical position termed situational ethics proposed by Joseph Fletcher. Fletcher (1966) advocates acting in a way that produces the most "Christian love", that is, the greatest amount of love fulfillment and benevolence. For Fletcher it is crucial when making moral decisions to be fully aware of all the facts surrounding the case, as well as the probable consequences of each alternative. But he also argues that after all calculations have been completed, one must choose the act that will best serve "love" as defined in the Christian tradition.

Fletcher views situational ethics as one of three primary avenues for making moral decisions. The other two are: (a) the legalistic, which contends that moral rules are absolute laws that must always be obeyed; and (b) the antinomian, which contends that no guidelines exist, that each situation is unique and requires a new decision. Among the weaknesses of utilitarianism are: (a) it seems to ignore actions that are wrong in themselves - with utilitarianism the ends justify the means which sometimes can be unethical; and (b) the principle of utility may come into conflict with that of justice. The views of utilitarianism seem to come out of the writings of Douglas Sherwin. Sherwin (1983) asks the question "what does it mean to be an ethical business person?" In order to answer that question he presented business as being a system of interdependent members that can thrive only when all its members are given equal emphasis. So, "to act ethically a manager has to ensure that the owners, employees, and customers all share fairly in the business's gain". Sherwin also argues that the American society has purposefully left a place for business among its institutions to secure economic performance in the production and distribution of goods and services. It follows that business leaders have the responsibility to try to deliver the benefits society seeks through this strategy. The values that govern their behavior must therefore be grounded in this purpose, must be implement it, and must be constrained by it. Sherwin seems to argue that a business person is behaving ethically if he/she behaves according to the society's best interest. His view seems to correspond with the view of utilitarianism.

\section{Single-Rule Nonconsequential Theories}

Whereas consequential theories argue that we should consider the consequences of an action in evaluating its morality, nonconsequential theories contend that we should consider other factors. Some such theories have even argued that we should not consider consequences at all. One such theory found considerable acceptance in business: the Golden Rule.

\section{Golden Rule}

In modern culture, the Golden Rule is most commonly interpreted as, "Do unto others as you'd have them do unto you". It commands us to treat others the way we would want to be treated. The other single-rule of nonconsequential theory is credited to Kant (1959).

\section{Kant's Categorical Imperative}

Kant's ethical theory stands as the premier illustration of a purely deontological theory, one that attempts to exclude a consideration of consequences in ethical decision making. To understand Kant's theory one should grasp the concept of "good will" or, in a loose interpretation, good intentions. Contained in good will is the concept of duty. Only when we act from duty do our actions have moral worth. Still we are left wondering what duties we have and how we can know them. Kant believes that through reason alone we could arrive at a moral law, based not on religion like the Golden Rule, nor on empirical evidence relating to consequences as in utilitarianism. If we arrive at such a law, it would oblige everyone without exception to follow it. Kant believes that he formulated such a law in his "categorical imperative". Kant's categorical imperative says that we should act in such a way that we could wish the maxim or principle of our action to become a universal law.

\section{Multiple-Rule Nonconsequential Theories}

Unlike single-rule nonconsequential theories, some nonconsequential theories, while relying on factors other than consequences in determining the morality of an action, appeal not to one rule, but several. Three such theories deserve special attention: Ross's prima facie duties, Rawl's maximin principle of justice, and Garrett's principle of proportionality.

\section{Ross's Prima Facie Duties}

Ross's theory is seen as an attempt to join aspects of utilitarianism with those of Kantianism. Ross (1939) believes that it is necessary to introduce consequences into ethical decision making while insisting that 
consequences alone do not make an act right. Ross contends that there are duties or obligations which bind us morally. In any ethical decision, we should weigh options with respect to the duties involved, and from the alternatives determine the duty that is most obligatory. So, an act may fall under a number of duties. For example, a business person may have the duty to maximize profits and, at the same time, be obliged to refrain from injuring people. The problem here lies in choosing the most obligatory duty. To solve this problem Ross proposes "prima facie duties". The term prima facie means "at first sight" or "on the surface". By prima facie duties, Ross means the duties that at first sight dictate what we should do when other moral factors are not considered. In other words, a prima facie duty is one we recognize at first sight as being obligatory when all other things are equal and when there are no conflicting duties.

\section{Rawl's Maximin Principle of Justice}

Rawls (1971) proposes a theory of ethics that tries to use the strengths of consequential and nonconsequential ethics while avoiding their pitfalls. Rawls proposes two principles to ensure justice: the equal liberty principle and the difference principle. By equality Rawls means the impartial and equitable administration and application of rules which define a practice. In other words, each person participating in a practice or affected by it should have an equal right to the greatest amount of liberty that is compatible with a like liberty for all. Crucial to any theory of social justice is the determination of when inequality is permissible. After all, a just society is not one in which all are equal, but one in which inequalities are justifiable. Rawls addresses this problem with his difference principle. The difference principle defines what kinds of inequalities are permissible. It specifies under what conditions the equal liberty principle may be violated.

\section{Garrett's Principle of Proportionality}

According to Garrett (1966), any moral decision involves three elements: what we intend, how we carry out the intention, and what happens (or intention, means, and end). We have seen that consequentialists are primarily concerned with the end of an action, whereas non-consequentialists generally put more emphasis on the intention behind it (as in Kant's case) or on one or more characteristics of the means itself. In the proportionality principle, Garrett brings together intention, means, and end to form a synthesis. Garrett's principle of proportionality states: "I am responsible for whatever I will as a means or an end. If both the means and the end I am willing are good in and of themselves, I may ethically permit or risk the foreseen but unwilled side effects if, and only if, I have a proportionate reason for doing so" (Garrett, 1966: 8).

\section{Ethical Relativism}

Protagoras, a Greek philosopher who lived in the fifth century B.C., seems to have believed two things: first that moral principles cannot be shown to be valid for everybody; and second, that people ought to follow the conventions of their own group. Protagoras's views can be classified as forms of ethical relativism. The term "ethical relativism", however, is used in different senses. Sometimes one is said to be a relativist if he thinks that an action that is wrong in one place might not be in another. If relativism is used in this sense, then practically everyone is a relativist, for practically everyone believes that certain circumstances make a difference to the morality of an act. Other times one is said to be a relativist if he believes: (a) that different social groups sometimes have different values and ethical opinions, and (b) an individual's values are nearreplicas of the values of his group.

The previous ethical theories have been accused of "ethical absolutism" because they suggested that there is only one true ethical code. Robin (1980) argues that an extreme version of ethical relativism "takes the position that, since there are two sides to every moral dilemma, and since every individual is entitled to their own system of values, neither side is more correct than the other" (p. 142). This extreme position would not be very helpful to marketers faced with important ethical decisions. A more moderate version of ethical relativism is presented excellently by Robin: According to the philosophy of ethical relativism, limited moral principles are open-ended in several respects. These philosophers believe that there are no moral principles which constitute a complete solution for every moral circumstance. They believe that there can be no resolution of a moral problem which is equally satisfactory for all people or for all time. They also believe that circumstances are constantly changing in important respects and that these changing circumstances produce the need for constant reevaluation of basic values and moral principles. Thus, moral decisions are always tentative and risky, but they are also constantly necessary. It is apparently true that societies throughout the world and over time have always held people responsible for their actions. In addition to being held responsible by others, the individual must constantly answer to his severest critic - his own conscience... Under the ethical relativist's philosophy, no theoretical work can provide complete and concise advice on specific decisions. At best, it can explain the 
means for making moral decisions and suggest the methods that are involved (p. 142). The major implication of ethical relativism is that all moral norms are relative to particular cultures. The rules of conduct that are applicable in one society do not apply to the actions of people in another society. Each community has its own norms, and morality is entirely a matter of conforming to the standards and rules accepted in one's own culture. To put it simply: What is right is what my society approves of; what is wrong is what my society disapproves of" (Tsalikis and Fritzsche, 2012). As our modern interconnected world, societies may become subject to foreign intervention by international courts if they are deemed to be violating basic human rights.

All the afore mentioned ethical theories assume in their core a deterministic, clockwork Newtonian world were cause and effect is straight forward and clear; were an action leads to a predictable reaction. However, this clockwork, predictable world has been upended by chaos theory, quantum physics and the idea of unintended consequences.

\section{Unintended Consequences}

While the concept of unintended consequences dates back to John Locke, it was popularized by the 20th century sociologist Robert Merton (1936). According to Merton, unintended consequences are unforeseen outcomes that were not intended by the original action. While the image that comes naturally with unintended consequences is usually negative, sometimes the consequences can be positive.

Similar to Murphy's law, the law of unintended consequences results from an attempt to intervene in a dynamic system creating anticipated and undesirable outcomes; hence being a warning against the hubristic belief that humans can exert control on the world around them.

Famous examples of unintended consequences include the Prohibition of alcohol in the US that led to the funding of organized crime and the death of many people drinking industrial alcohol laced with poisons. In Afghanistan the CIA funded anti-Russian groups that eventually morphed into the Taliban. Seat belts saved the lives of many adult drivers but also contributed to many deaths of infants improperly placed in the front seat. In the field of ethics as a personal experience, many times the author gives money to street beggars. While feeling he has helped them, he might me contributing to organized crime by perpetuating the enslavement of these street-people as famously depicted in the movie "Slumdog Millionaire".

The concept of unintended consequences is related to the idea of determinism and the ideas of chaos theory.

\section{Determinism}

Determinism is the Newtonian perception of the world as a clockwork, where a cause is always followed by a predictable effect. It assumes that causation is absolute and all events, are completely determined by previously existing causes. That predictability includes our moral choices and actions. We instinctively assume that a good deed will result in a good outcome. It is the basis for many religions espousing good deeds as a prerequisite to the afterlife. This predictable notion of our world was shattered by the ideas of Einstein and Quantum theory were in certain situations an effect is followed by a cause. Most of Quantum physics are probabilistic and random. This random nature of physics is the core of Chaos Theory.

\section{Chaos Theory}

Starting with Newton (gravity, calculus) scientists perceived the world as a mechanistic "clockwork" world which could be measured and predicted. A purely deterministic, predictable world. Beginning in the 1960s, chaos theory has been changing our way of understanding the universe.

With the introduction of computers the discovery of chaos became possible. For example, you take a simple formula like: $\mathrm{y}=\mathrm{x}^{2}+\mathrm{c}$ and plug it in the computer. For each $\mathrm{x}$ you get a corresponding $\mathrm{y}$. This gives you two points which you can plot on a graph as a dot. Then you take the value of $\mathrm{y}$ plug it in as the new value of $\mathrm{x}$ and continue this loop a gazillion times. The picture you see on the screen is the weird pear like black shape at the beginning of the video (the Mandelbrot set).

With today's computers we can perform these calculations extremely fast. So what you see on the video is the focusing on a smaller and smaller section of the Mandelbrot set. You see areas of chaos and areas of determinism (the familiar Mandelbrot pear shape). The video ends with the same shape. The lesson is that our universe has areas of determinism (the pear shape) and areas of chaos (the other ever changing shapes).

With different simple formulas, and by sheer repetition of a simple formula, we get the shape of leaves, trees and mountains. This is an explanation of evolution (the repetition over millennia of a simple formula). 
Chaos theory is a new science that has drastically changed our understanding of scientific phenomena. It has significantly affected physics and has also moved into other fields like economics and psychology among others. Chaos theory might also change our understanding of the consumer. The three major implications of chaos theory on consumer behavior are:

\section{Sensitivity to Initial Conditions}

Traditional thought has it that very small influences can be neglected. If you want to effect a large influence on the end results you need a large change in the initial conditions. In the 1960s, Lorenz, in an effort to develop a model to predict the weather, stumbled on to what eventually became the "butterfly effect" (Lorenz, 1963). Lorenz entered the temperature, barometric pressure and wind speed measurements in his analog computer and out came the prediction that there would be rain. A consequent run, using the same computer, same models, and the same data resulted in a prediction of no rain. How could the same inputs come up with so diametrically opposing outputs? Lorenz discovered that inputting a temperature of .507 in the weather model would give completely different results than inputting .506 (the analog computer was randomly assigning either .507 or .506). This apparently inconsequential one part of a thousand of a degree led to completely different weather predictions.

This discovery led to Lorenz's "butterfly effect" where a butterfly flaps its wings in Japan disturbing so slightly the molecules of air around it. This small disturbance cascades down to the eventual creation of a hurricane in the Atlantic.

Chaos theorist like to use the cigarette smoke to explain the sensitive dependence on initial conditions concept (Schroeder, 1996). In observing a lit cigarette, smoke comes out of the cigarette in a very regular deterministic column. A few seconds later the deterministic column dissolves into a chaotic unpredictable swirl. To explain what is happening, let's consider two smoke particles as they float in the deterministic column. There is an exceedingly miniscule difference in the air pressure between these two smoke particles. In a few seconds this initial trivial difference in air pressure would lead to a relatively large distance between the two smoke particles.

The idea of sensitivity to initial conditions could have profound implication in marketing. It says that in order to change consumer behavior we might not have to implement "big" changes, but "small" changes might work as well. For example, change only the pitch of the voice of the announcer of the commercial or change the price from $\$ 19.95$ to $\$ 19.98$.

This idea of sensitive dependence on initial conditions could have profound implication on our causal understanding. It might be possible that a small ethical act leads to a large unethical consequence or vice versa.

In ethics, traditional utilitarianism, as expressed by John Stuart Mill and Jeremy Bentham (Cavanagh et al., 1981), judges an act by its consequences. Utilitarianism assumes a causal relationship between an unethical act leading to grave consequences either to the individual (egoism) or to society in general. This thinking implies that a great ethical injustice has to be preceded by a great unethical act. In other words, unethical acts of a small degree would not lead to great degree of suffering. The "butterfly effect" argues that even small and apparently inconsequential acts, regardless of its ethicality, could lead to great degrees of injustice and suffering.

\section{Dimensionality}

Chaos theorists use the perception of a car to explain the concept of dimensionality (Gleick, 1987). A car from a great distance would appear to you as a dot. A dot has zero dimensions. As you move closer to the car you would be able to discern the outline of a car. This is the two dimensions of height and width of the car. As you move even closer it is possible to perceive the three dimensional image of the car. When you put your eyes inches from the roof of the car you can only perceive the two dimensional space of the roof. Even further you can see a paint molecule. From a distance the paint molecule is a zero dimensional dot. Getting closer to the paint molecule you can see the two dimensional outline of the molecule and so on at infinitum. At every distance of perception the object of study has a different dimensionality or it appears different to the observer.

In marketing research, our measurement of the customer will depend on the "distance/dimensionality" we evaluate them by. For example, if you ask a few questions in a questionnaire, you will not get too much information (close to 0 dimensions). Freudian methodologies will move in closer to the consumer and capture more dimensions. Ultimately, if you follow the same customer for a year using many qualitative methodologies, you will get a better picture (more dimensionality). 
In ethics, our evaluation of an ethically sensitive act will depend from the "distance" we evaluate the act from. The dimensionality of the act will depend on the standpoint of the observer. This standpoint could be temporal, cultural, or based on the proximity of the evaluator to the act.

\section{Areas of Determinism Followed by Areas of Chaos}

One of the typical experiments in chaos theory involves a small container full of a gas and a heating torch under it. At small temperatures the heat passes through convection without disturbing the gas molecules. At higher temperatures the gas molecules at the bottom of the container rise to the top where they lose their heat energy and fall to the bottom again forming a quite regular circular formation. Within a certain temperature range, that circular movement of the gas molecules is deterministic and predictable. As the temperature increases the regular movement becomes chaotic. As the temperature increases even further, the movement of the gas molecules goes through stages of determinism followed by chaos and so on. In some temperature ranges the direction of the gas flow even reverses.

This phenomenon might have profound implications for consumer behavior. Consumers under certain conditions will behave in a deterministic predictable way, while under other conditions behave irrationally (chaotically). Under yet other conditions, they might even reverse a strong liking for a product to a strong disliking for it.

This phenomenon might have profound implications for human behavior and more specifically human ethical behavior. Humans react to certain high or low "pressures" that affect their ethical behavior. Within certain ranges these "pressures" might create a deterministic ethical behavior. However, other ranges of "pressures" might create chaotic ethical behavior. Even more intriguingly, within certain high or low "pressure" ranges ethical behavior might be reversed from ethical to unethical and vice versa.

\section{Conclusion}

The aforementioned concepts of determinism, unintended consequences, and chaos theory negate the idea that an ethical act is always followed by an ethical result. Sometimes the opposite might happen, and ethical act could be followed by an unethical result. Our world is to too chaotic and dynamic to predict the causal effects of ethical actions. Of course, that does not mean we are excused to making unethical decisions, it means that we need to approach the idea of ethics from an experimental point of view. We should measure not what the ethical act is supposed to result in, but what the ethical act actually/experimentally results in. The focus should not be whether people perceive an act as ethical or unethical but rather to experimentally observe the actual unpredictable results of these ethical or unethical acts. Of course, the situation becomes more complex when a small change in the initial conditions of the act can lead to drastic changes in the final result. This idea is closer to the Consequential theories of ethics. In a way, the deontological conceptions of ethical behavior might not "apply" or predict the final results of the action.

\section{References}

1. Barry, Richmon (1979a). Can we prevent questionable foreign payments? Business Horizons 22(June), 14-19.

2. Barry, V. (1979b). Moral issues in business, 39-70. New York: Wadsworth Publishing Co.

3. Beauchamp, Tom L., and Norman, E. Bowie (1983). Ethical theory and business, 2nd ed. EnglewoodCliffs: Prentice Hall, Inc.

4. Cavanagh, Gerald F., Dennis, J. Moberg and Manue,l Velasquez (1981). The Ethics of Organizational Politics, Academy of Management Review, 6(3), 363-374.

5. DeGeorge, Richard R. (1982). Business ethics, 2nd ed. New York: Macmillan Publishing.

6. Fletcher, Joseph (1966). Situation ethics: The new morality, 95. Philadelphia: Westminster Press.

7. Garrett, Thomas (1966). Business ethics. Englewood Cliffs: Prentice Hall, Inc.

8. Gleick, James (1987). Chaos: Making a New Science, (Penguin Books, NY).

9. Kant, Immanuel (1959). Foundations of the metaphysics of morals. Trans. Lewis White. New York: BobbsMerrill.

10.Lorenz, Edward N. (1963). Deterministic Non Periodic flow, Journal of the Atmospheric Sciences 20, 130-141.

11.Merton, Robert K. (1936). The Unanticipated Consequences of Purposive Social Action, American Sociological Review, 1(6), 895.

12.Rawls, John (1971). A theory of justice. Cambridge, MA: Harvard University Press.

13.Robin, Donald P. (1980). Value issues in marketing. In Theoretical developments in marketing, ed. C.W. Lamb and P.M. Dunne, 142-145. Chicago: AMA. 
14.Ross, William D. (1939). The right and the good. Oxford: Clarendon.

15.Runes, Dagobert D. (1964). Dictionary of philosophy, 98-100. Patterson: Littlefields, Adams and Co.

16.Schroeder, Manfred (1996). Fractals, Chaos,Power Laws, (Freeman and Co., NY).

17.Sherwin, Douglas S. (1983). The ethical roots of the business system. Harvard Business Review 61(November-December), 183-192.

18. Taylor, Paul W. (1975). Principles of ethics: An introduction. Encino: Dickerson Publishing Co., Inc.

19.Tsalikis, John and David, J. Fritzsche (2012). Business Ethics: A Literature Review with a Focus on Marketing Ethics, Journal of Business Ethics, commemorative issue of "classic" articles.

20.Vitell, Scott J. Jr. (1986). Marketing ethics: Conceptual and empirical foundations of a positive theory of decision making in marketing situations having ethical content. Unpublished dissertation, Texas Tech University. 